\title{
Evolution of Physician-Centric Business Models Under the Patient Protection and Affordable Care Act
}

\author{
Tanya Nix \\ Walden University \\ Lynn Szostek \\ Walden University
}

\begin{abstract}
For decades, the cost of medical care in the United States has increased exponentially. United States citizens spend twice as much as their European counterparts on medical care. Congress enacted the Patient Protection and Affordable Care Act (PPACA) to ensure affordable healthcare to the citizens of the United States. PPACA legislation is creating a new paradigm in healthcare delivery and provider business models. The purpose of this case study was to explore physicians' perspectives regarding physician-centric business models evolving under the requirements of the PPACA legislation. Data were gathered through semistructured interviews and questionnaires with a purposive sample of 75 participants across 20 medical specialties within the United States. Three universal themes emerged including (a) use of midlevel practitioners, (b) changes to provider practices, and (c) enhanced business education. Healthcare leaders may use the findings to advance the evolution of physician business models that meet the needs of healthcare stakeholders.
\end{abstract}

Keywords: Affordable Care Act, ACA, physician-centric business, physician, Patient Protection and Affordable Care Act

\section{Foundation of the Study}

The cost of medical care in the United States continues to increase with cost levels greater than that of comparable countries (Malach \& Baumol, 2012). The United States currently ranks number one in the world in healthcare spending per capita but 37th in health outcomes (Murray \& Frenk, 2010). In 2010 , Americans spent nearly $\$ 2.6$ trillion or $\$ 8,000$ per person for medical care (Martin, Lassman, Washington, \& Catlin, 2012), compared to half that amount by their European counterparts (Ginter $\&$ Simko, 2010). The problem of disproportionate spending on medical care compared to health outcomes became the impetus for the implementation of the Patient Protection and Affordable Care Act (PPACA) of 2010. PPACA legislation is creating a new paradigm in healthcare reform and evolution in the delivery of healthcare and provider business models.

The purpose of this qualitative case study was to explore how physician-centric business models might evolve under the requirements of PPACA legislation from the physician perspective. Exploration of physician perspectives consisted of various components of healthcare business models such as organizational design, the delivery of care, and physician reimbursement/costing methodologies. With full implementation of PPACA legislation expected through 2019 (Marco et al., 2012), there is little information available regarding the impact that legislation has had upon physicians and their current business models from the physician perspective. 
Assumptions in conducting this study included that participants provided adequate responses to the interview questions disclosing truthful information without bias. Second, participants were representative of the population under investigation and were normally distributed. Finally, that the qualitative case study was the appropriate research method and design to explore how current physician-centric business models are evolving under the requirements of PPACA legislation. The study had limitations to include in time and scope; the data were cross-sectional and were only taken from 75 physicians. We acknowledge that although the results may suggest patterns of response among physician leaders, we could not apply the conclusions to a broader population.

\section{Purpose Statement}

The purpose of this qualitative case study was to explore how current physician-centric business models are evolving under the requirements of PPACA legislation from the physician perspective. The population consisted of 75 physicians with independent medical practices of various disciplines located throughout the Unites States. This population was appropriate for this study because physicians are the primary providers of medical care influencing patient health outcomes, and they provide information-rich data regarding the phenomenon. The business and social ramifications of this study might be realized through the development of healthcare business models that meet the needs of all stakeholders under the new paradigm of PPACA legislation.

\section{Research Design}

For this study, using a case study design was advantageous for exploring the experiences of physicians within the paradigm of PPACA legislation and how this legislation has impacted the physician-centric business model. The use of open-ended, semistructured questions provided us with in-depth answers for exploration of the phenomenon. The data collection process for this study involved primary data from participant interviews and questionaires in addition to documentation from previous formal studies discussed within the literature review, the PPACA legislation, and government reports.

\section{Research Question}

The following central research question guided this study: How might physician-centric business models evolve under the requirements of the PPACA legislation from the physician perspective? We also used the following interview questions to solicit responses for catalyzing the rich exploration of the evolution of physician-centric business models from the provider's perspective:

1. Please describe your medical practice regarding medical specialty, years in practice, and the type(s) of practice organizations you have been involved in throughout your career.

2. In the general sense, what is your opinion of PPACA legislation?

3. How did you receive the education or training to conduct your business?

4. Specifically, how has the administrative/regulatory climate of healthcare affected the operations of your practice since 2009 ?

5. What types of reforms do you anticipate to physician reimbursement given the legislative push toward value-based care?

6. What types of changes do you foresee to the delivery of medical care for your practice?

7. Since the passage of PPACA legislation in 2010, have you experienced any positive or negative changes taking place in your practice and what were they?

8. To accomplish the goals of decreasing healthcare costs and increasing quality, do you feel there is a need to evolve your business model? Why or why not? 
9. What type of business model do you foresee as a viable alternative to the physician-centric model?

10. How do you perceive the four structures for physician-centric business models (patientcentered medical homes [PCMHs], accountable care organizations [ACOs], physicians as employees, and concierge medicine) that may affect the way you conduct your business? Would you consider participating in an ACO or PCMH as outlined under PPACA legislation? Why or why not?

11. What is the most significant effect PPACA legislation will have upon the viability of your practice in the future?

12. Is there anything else you would like to add that might not have been addressed by these questions?

\section{Definition of Terms}

Patient-centric care: The process of viewing medical care from the perspective and experience of the patients and their families (DiGioia, Fann, Feng, \& Greenhouse, 2013).

Physician-centric care: The process of delivering reactive patient care where a physician is solely responsible for the patient's care and flow of information (Longworth, 2013).

Provider: An individual or company providing medical care and services to a patient or the public (Proctor \& Young-Adams, 2011).

Reimbursement: Payment of benefits to a medical provider for services rendered according to the guidelines of third-party payers (Proctor \& Young-Adams, 2011).

Third-party payer: A person or organization, other than the patient, responsible for paying all or part of a patient's medical costs (Proctor \& Young-Adams, 2011).

\section{Population and Sampling}

This study included the use of purposive sampling with 75 participants throughout the United States. All participants were physicians within various medical disciplines, owning an independent medical practice, having between 5 and 40 years of experience. A purposive sample of this population allowed us to garner data from professionals with experience in healthcare business management, billing and coding, and the regulatory climate of the medical industry.

\section{A Review of the Professional and Academic Literature}

The U.S. Congress has been developing various governmental regulations for physician reimbursement by creating fee schedules, diagnosis and procedure coding, and fee calculation formulas for decades. Improving the effectiveness and efficiency of the physician reimbursement system as a means to decrease healthcare costs was one such effort leading to the development of the PPACA of 2010. In 2010, Congress enacted the PPACA in an attempt to decrease healthcare expenditures and increase the quality of care for all Americans (Kocher \& Sahni, 2010).

The need for organizational models that deliver value, efficiency, and cost-effective care is one intended outcome of the PPACA. However, there was little information in peer reviewed literature regarding how PPACA legislation may affect practice models from the physician perspective. Moore and Wasson (2007) described a traditional physician-centric practice as having high overhead, minimal performance data, and reactive, volume-driven patient care. Therefore, reforming the 
delivery of healthcare with a patient-centered focus under PPACA legislation may require extensive changes to traditional physician-centric business models.

\section{Organizational Models for the Delivery of Care}

Physician business models include diverse organizational structures such as independent practices, associations, partnerships, and group practices. Most independent physician practices operate on a model that emphasizes physician autonomy with employees supporting the treatment of patients in a front (clinical) and back (administrative) organizational structure. Zonies (2009) acknowledged that independent physicians must possess both medical acumen and business knowledge, thus creating additional constraints. Wolinsky (1982) noted that the independent practice structure is the most unstable because it is either acutely patient-dependent or referral-dependent. Associations and partnerships allow physicians to maintain independence while forming cooperative arrangements, taking advantage of economies of scale, and sharing ancillary staff. Group practices provide the security of sharing financial risk, economies of scale, and profit sharing but require peer regulation, and bureaucratic mechanisms to manage the diverse operational requirements (Wolinsky, 1982).

\section{Concierge Medicine}

An emerging trend in physician-centric practices is the concept of concierge or retainer medicine that provides enhanced care to patients beyond traditional physician practices. French et al. (2010) defined concierge medicine as a business arrangement between physicians and patients that includes a membership fee entitling the patient to a variety of services such as same-day or next-day appointments for nonemergency care, 24/7 access to a provider, house calls, and preventative services not normally offered through most health insurance plans. Huddle and Centor (2011) acknowledged benefits for physicians including decreases in patient loads, fewer administrative requirements, more personalized attention to patients, and a more fulfilling practice experience. While there is a potential for concierge medicine to become an innovative physician-centric business model, concerns exist regarding costs, ethics, and access to medical care.

\section{Physicians as Hospital Employees}

Hospital administrators are responding to healthcare reform by employing physicians in salaried positions or by making them independent contractors. Hunter and Baum (2012) surmised that traditional employment is an unfamiliar concept to physicians and creates uncertainty in their role as a physician employee. Hunter and Baum also suggested that the need for financial security and the risk of business viability under the PPACA; physicians are seeking employment opportunities outside of the traditional independent provider model.

Hospital administrators realize the necessity of employing physicians because aligning revenues with physicians and other healthcare providers may be the most optimal means to satisfy the requirements of PPACA regulation. Yet, with new physician-hospital employment models, questions arise concerning how Stark and antitrust laws may affect integrated care models. Iglehart (2011) suggested that choosing integrated and employment models can create a risk of illegal price fixing when engaging in joint price negotiations with insurance carriers in less competitive markets. Payton (2012) also noted that hospitals hiring physicians cannot structure compensation arrangements for direct utilization of ancillary services because of Stark laws; therefore, compensation packages for physician employment may require a combination of salary and incentive payment for performance. With the financial viability of physician-centric practices in jeopardy under the healthcare reform environment, physician employment may provide an innovative organizational structure offering physicians and hospitals a model for long-term sustainability. 


\section{Proposed Changes to Healthcare Delivery Under PPACA Legislation}

With the enactment of PPACA legislation, physician reimbursement reform is at the forefront of debate regarding how to control healthcare expenditures and improve the quality and value of medical services. Physician reimbursement reform also requires discussion regarding the future delivery of medical services and how physician-centric business models may evolve under the requirements of PPACA legislation. Concepts that are pertinent to the healthcare reform process include the formation of PCMHs and ACOs.

\section{Patient-Centered Medical Home}

The PCMH is a model of care in which a primary provider manages and coordinates the care of all facets of a patient's health with a team of healthcare providers. The Agency for Healthcare Research and Quality (2013) defined the PCMH as an organizational model for primary care that delivers the core functions of primary medical care. The establishment of PCMHs involves the transformation of physician-centric care processes incorporating all members of a healthcare team, placing the patient at the center of care to improve the quality and the access of healthcare teams to the patient.

The main impetus of the PCMH concept is to deliver high quality medical services at a lower cost to increase the value of medical care. Goldsmith (2011) noted many physicians are experiencing issues with business viability because growth in reimbursement lags behind the rate of growth in business expenses. Additionally, Berenson and Rich (2010) suggested fee-for-service payment methodologies do not accurately reflect the amount of time and activities to treat the increasing complexity of disease processes in various patient populations, thus decreasing the quality of patient care. This situation has forced physicians to practice volume billing and increase ancillary testing services to accommodate for income losses. Furthermore, Berenson and Rich asserted the current model of reactive patient care that emphasize documenting patient histories, performing physical exams, and clinical decision-making are no longer suitable for capturing the amount of care activities necessary for patients with chronic health conditions. Goldsmith (2011) and Longworth (2013) noted that the PCMH model involves moving away from reactive care under a physician-centric model toward a proactive, patient-centric care model. Proactive care tracks the health of patients over time, with an emphasis on wellness and chronic disease management to prevent unnecessary emergency room visits and hospital admissions.

\section{Accountable Care Organizations}

ACOs are the first healthcare delivery reform initiative under PPACA legislation. Berkwick (2011) suggested that the purpose of the ACO is to improve medical care for individuals, create better health outcomes for populations, and decrease the growth in aggregate healthcare costs. While the exact definition of an ACO varies, McClellan, McKethan, Lewis, Roski, and Fisher (2010) noted experts do agree upon the core concepts and further define ACOs as consisting of a group of providers jointly responsible for quality improvements and reduction in healthcare spending.

ACOs involve various organizational structures ranging from integrated delivery systems and physician medical groups to hospital-based systems. Kocher and Sahni (2010) asserted the move toward ACOs will transform the structure of physician practice models because ACOs integrate hospital services and physician practices. McClellan et al. (2010) suggested ACOs should include participation of physicians, hospitals, long-term care organizations, and other providers to improve quality and lower healthcare costs. Under the Department of Health and Human Services (2011), ACOs will have considerable flexibility regarding organizational structures, with requirements to meet quality standards in patient safety, care coordination, and preventative health. The organizational structures of ACOs are emerging from diverse healthcare practice models. Shortell, 
Casalino, and Fisher (2010) suggested these models include integrated systems that combine hospitals, physicians, and insurance companies, multispecialty group practices, physician-hospital organizations, IPAs, and virtual physician organizations. Shields et al. (2011) cited four key challenges to implementing ACOs: (a) the preponderance of solo and small group medical practices in the United States, (b) hospital administrations' failures to engage physicians as leaders, (c) fee-forservice reimbursement, and (d) the need for ACOs in the commercial market. Additionally, Shields et al. noted independent and small group practices lack the capital to invest in quality improvement training, information technology, and the development of disease registries to develop ACOs. Medical staff structures of hospitals rely upon independent physicians practices, which have not demonstrated a capability to improve quality and safety quickly, remove poorly performing physicians from staff, and reward physicians for performance, thus making integration of medical staff challenging (Shields et al., 2011). Furthermore, many areas of the United States do not have integrated systems, especially in rural communities, making national ACO implementation difficult.

\section{Research Method}

Yin (2014) suggested the use of diverse sources of evidence for case study research because it allows researchers to strengthen the accuracy and validity of the study. Data from interviews and questionnaires were triangulated with the findings from formal research studies, industry articles, and government reports.

After transcribing the interviews into a Word document, NVivo 10 software program was used to assist with coding and sorting data into themes for analysis. This allowed us to organize the data for coding, data linking, content analysis, and findings confirmation.

Because we had professional relationships with a few of the physician participants, emphasis on triangulation and reflexivity were the means we chose for reducing the potential for bias.

Additionally, Houghton, Casey, Shaw, and Murphy (2013) noted that an advantage of using case study research is the opportunity to use diverse data sources through methodological triangulation, thus providing a complete representation of the phenomenon. Therefore, the use of methodological triangulation improved our understanding of the complex nature of the phenomenon while allowing us to explore the subjective experiences of the physicians objectively.

\section{Ethical Research}

There was minimal risk from participating in this study with the probability and degree of risk not greater than those ordinarily encountered in daily life. Additionally, the interview questions were not offensive or threatening, and there was no risk to financial standing, reputation or employability as the questions pertained directly to the individual physicians' practice structure. All individuals for this study volunteered for participation without coercion and signed an easily understandable informed consent form. While a few of the participants were business acquaintances, there was no conflict of interest, and there was no change in the relationship status because of participation or nonparticipation in the study. Accordingly, participants had the ability to withdraw from the study at any time by contacting us via phone or e-mail, and there were no incentives offered for participation in this study.

Data collection was through audio recordings and e-mail questionnaires, transcribed and uploaded into the NVivo 10 software system. A coding system for data identified participants for data analysis without reference to the participant's organization or practice name, through a numbering system, thus ensuring privacy and confidentiality. Each participant received an identifying label, such as 
Participant 1T or Participant 2L, which corresponded with the number of the participant interview or questionnaire.

Storage of all data including audio recordings, e-mail questionnaires, and transcriptions was via an encrypted computer file or locked file cabinet for 5 years, to protect the rights and identities of the participants. After 5 years, the destruction of the data will ensure the confidentiality of all participants.

\section{Reliability and Validity}

\section{Reliability}

In qualitative research, achieving reliability equates with the ability to duplicate the components of the study, the consistency of data collection, and accuracy of the data recording processes. Given this, a consistent process was followed by both researchers using the same semistructured questions and questionnaire. We conducted transcript reviews with participants for accuracy, ensured proper coding, and maintained a consistent process to capture and analyze data to ensure reliability.

\section{Validity}

Tracy (2010) suggested achieving credibility in qualitative studies includes a rich description and detailing of the personal experiences garnered from in-depth interviews with study participants. We used verbatim transcription of participant interviews and member checking to establish validity ensuring an accurate description of the experience. We identified themes through triangulating data from documentary evidence and participant interviews and questionnaires for assuring the validity of the study findings. In addition, the participant interviews and questionnaires continued past the point of data saturation to ensure no new or relevant information emerged.

\section{Results and Data Analysis}

\section{Unfavorable Opinion of PPACA Legislation}

The PPACA was new legislation at the time of this study, and little information was available in peer reviewed literature regarding physician opinions of the legislation. Of the limited information found in peer reviewed literature, Sommers and Bindman (2012) and Quaye (2014) noted physician opinions were mixed regarding the positive and negative aspects of the legislation. One industry survey suggested that only $44 \%$ of physician respondents thought the legislation was a worthy idea (Sommers \& Bindman, 2012). Quaye (2014) further noted $47.2 \%$ of respondents were opposed to the PPACA legislation.

The opinions of this study's participants were generally unfavorable of the PPACA legislation. At the time of this study, the implementation of the PPACA's individual mandate became a source of frustration for the American public regarding the government's mismanagement of the HealthCare.gov website (Kingsdale, 2014), likely accounting for the participants' negativity toward the legislation. The majority of participants suggested that the legislation's main objective of providing affordable health insurance for Americans was a sound idea; however, the design and implementation of the legislation was confusing and inadequate. Participants also suggested the legislation was too complex and stated the politics surrounding the legislation promoted the benefits of interest groups such as pharmaceutical, insurance, and technology groups rather than the interests of physicians, hospitals, and patients. These attitudes were consistent with industry articles cited in the literature review (Mazurenko \& O'Connor, 2012; Wolinsky, 1982; Zismer, 2011) 
regarding physician attitudes towards the loss of autonomy with government involvement in healthcare. Additionally, Zismer (2011) suggested the loss of autonomy as a viable reason for negative attitudes of physicians regarding nonphysician managers controlling medical and financial decision-making. Loss of autonomy was a key determinant of physician attitudes stemming from increasing regulatory environment for cost and quality accountability under the requirements of PPACA legislation. Examples of participants' responses included the following:

- "I think it is a poorly thought-out, haphazardly implemented, confusing and politically motivated legislation." (P19T)

- "The only observable effect of the PPACA on the individuals in our society is to increase the cost of insurance and, quite probably, to limit the availability of care." (P5T)

- "From my exposure to it, I think the pharmaceutical, insurance companies, different technology groups, and hospitals are benefiting the most from the legislation." (P14T)

- "Apparently crafted by insurance company lobbyists or people influenced by them, it seems to me that enriching insurance companies and centralizing control of healthcare with the federal government are the two principal objectives of this legislation." (P5T)

- "What the public needs to understand is that care is now significantly undermined by this legislation." (P7L)

- "Unfortunately, physicians are now facing a career change as regulations make it cost prohibitive to practice medicine." (P36L)

- "We feel held hostage by the legal and insurance parameters making it nearly impossible to practice medicine." (P42L)

- "Our practice is no longer taking patients with Medicare nor Medicaid. We simply could no longer afford to treat them." (P47L)

\section{Viability of Business Models Under PPACA Legislation}

We used the interview questions regarding the four structures for physician-centric business models (PCMHs, ACOs, physicians as employees, and concierge medicine) to enable rich exploration of the evolution of physician-centric business models from the providers' perspective.

\section{Patient-Centered Medical Homes}

The Agency for Healthcare Research and Quality (2013) defined the PCMH as an organizational model for primary care that involves the transformation of physician-centric care processes that incorporate the use of a healthcare teams to improve the quality and the access of care to patients. In documentation from the literature review (Berenson \& Rich, 2010; Longworth, 2013; Nutting et al., 2011), researchers noted that there are no set organizational frameworks for PCMHs, but they do rely upon diverse providers sharing in the care and the reimbursement of care. Unfortunately, the PCMH model may not generalize across patient populations because the frameworks are ill defined. Additionally, Nutting et al. (2011) asserted that the PCMH model bases organizational principles upon quality improvement measures and the use of practice-based care teams. VanVactor (2013) and Wise, Alexander, Green, and Cohen(2012) suggested the integration of PCMHs require significant expansion of the collaboration of healthcare providers across and within diverse care settings and requires an adjustment in the patient-mix regarding the range of medical services that the practice provides. Berenson and Rich (2010) further suggested reimbursement would require an adjustment for community-based entities that participate in extended patient care, while Longworth (2013) acknowledged that a caveat to community-based participation will be managing the costs associated with integrated care. 
Over half of the participants stated they were unfamiliar with the PCMH model and those who were knowledgeable, expressed diverse opinions that included the following:

- "The PCMHs sound like the old HMOs or gatekeepers to me." (P12T)

- "I think having a medical home is good, but most patients actually do that and pick a physician they like and stick with them. The only reason they would change is because of lack of access, and we see that a lot, or lack of quality." (P7T)

- "The PCMHs won't work in this area because of population." (P13T)

- "PCMHs would not work in our rural community, per se. We simply don't have the resources to manage cases nor are their community resources to provide an adequate patient care team. Sometimes we have to send patients to Chicago in order for them to get the specialized services they need." (P6L)

- "Been there done that, this is just like the HMO role we play as primary care physicians. It looks good on paper, but the reimbursement does not even begin to cover the costs." (P10L)

- "Our practice has embraced a patient-centric model form the start. We use technology to help partner with other providers and our patients. The most notable example is the confidential web-based medical record that the patient can access with a password. They can send me emails, see lab results, get prescriptions renewed, and other aspects that facilitate great care." (P25L)

\section{Accountable Care Organizations}

In documentation from the literature review (Berkwick, 2011; Longworth, 2013; McClellan, 2011; Shields et al., 2011), researchers noted several challenges in implementing the ACO business model because of the requirements for infrastructure to track patient populations and disease processes for performance measurement. Shortell et al. (2010) noted the ACO model includes an integrated system design that combines hospitals, physicians, and insurance companies, multispecialty group practices, and physician-hospital organizations. Participants in this study were in general, wary of integrating physicians and hospitals because of the challenges to medical governance felt by physicians.

Participant statements included the following:

- "I think ACOs and combining private physicians with hospitals for reimbursement is challenging as a whole." (P14T)

- "If you integrate physicians with hospitals so they have a sense of ownership and motivation, have certainty of governance, and are treated as partners, those types of systems can work. But if they feel they are driven in there because they have no other option, then that is not the best environment, productivity-wise. If they have no governance or no say so-it is not a good model." (P14T)

- "In order for ACO to work for us, we would need a better partnership with our hospital affiliates. Too many times we are 'dumped' on by the hospital placing us in delicate situations with our patients. Trust would definitely be required among partners in order for an ACO to be successful." (P19L)

- "Though I see the merit of ACO and, to some degree, practice this way I am skeptical after 37 years of practice that such a government-based program will really work." (P33L)

The Department of Health and Human Services (2011) stated that ACOs will have considerable flexibility regarding organizational structures, with requirements to meet quality standards in patient safety, care coordination, and preventative health. However, Shields et al. (2011) surmised that independent and small group practices lack the capital to invest in the required infrastructure for ACO development. Many areas of the United States do not have integrated systems, especially in 
rural communities, making national ACO implementation difficult. Several participants mirrored these concerns with comments that included the following:

- "The accountable part is what bothers me because again, just like the outcome-based payment, accountable to who?" (P15T)

- "ACOs are a new concept, but if everyone is on the same page regarding communication, software and electronics, patients can be tracked; otherwise it is difficult for patients to have any continuity between providers." (P7T)

- "These organizations will not fly in the rural areas because there is not enough population." $(\mathrm{P} 13 \mathrm{~T})$

- "I am a large supporter of the electronic health record and integrated systems aspect. The concern is who will determine the 'accountability' part of this initiative." (P14L)

- "We are a practice that covers a three county rural community. We do not have the integrated systems to be successful under ACO.” (P37L)

- "I can see the merit of such a 'program' in helping reduce patient safety issues particularly around medication errors and missed diagnoses by virtue of better care coordination. However, communication, as always, will be the key!" (P42L)

While more participants in this study were familiar with ACOs than PCMHs, the majority voiced concerns regarding the feasibility of these organizational structures within the United States. When participants were asked if they would consider participating in an ACO or PCMH, responses included the following:

- "Only if forced to do so for lack of other options." (P16T)

- "No, I would not participate in an accountable care organization." (P2T)

- "Probably not, because patients choose their different providers anyways and we are just not set up in this area for a more formal type of organization. Again, it comes down to access issues in rural areas." (P7T)

- $\quad$ No, I cannot keep changing my organizational structure to suite the ever-changing political climate." (P3L)

- "No, these programs and the entire ACA is not about patient care, it is about money and politics." (P14L)

- "I am actually working on a business model that blends the attributes of both of these. The trick is doing so under the current regulations and reimbursement requirements." (P25L)

- "I just want to practice medicine. Lately, I feel like I practice politics." (P52L)

\section{Physicians as Employees}

When exploring the perceptions of physicians as employees, the majority of participants cited the probability that physicians will become employees of hospitals or large physician groups in the future because of increasing financial hardships under PPACA legislation. Participant views were consistent with research from the literature review (Hunter \& Baum, 2012; Iglehart, 2011; Jones \& Trieber, 2010) regarding future physician employment as a result of PPACA legislation.

Additionally, Jones and Treiber (2010) suggested that dissatisfaction with managed care and threats to financial security are reasons for seeking employment opportunities outside of the traditional independent provider model. In a study by Charles et al. (2013), researchers noted over half of practicing physicians in the United States are employed by hospitals or large group practices with an increasing number of rural surgeons entering into employment contracts with hospitals. Charles et al. further cited several reasons for these trends including decreasing reimbursement, malpractice risk, and long work hours. Participant statements regarding physician employment included the following: 
- "I believe strongly that in 10 years, $90 \%$ of all physicians will be employees." (P10T)

- "In the future, physicians will probably be employed by hospitals or some large entity." (P13T)

- "Many doctors are opting for an employment-based practice because it's financially feasible." (P15T)

- "II see more employed physicians and much less private practice." (P4T)

- "I see physicians moving toward being employed by hospitals and concierge practices." (P6T)

- "Not sure employing physicians is the answer. It is the system that is broken." (P2L)

- "Many of my friends have now chosen the employment route if only to get relief from their md school loans and to get a guaranteed salary." (P5L)

- "I am not sure there is truly a difference between an employed practice from a private practice. But time will tell as that seems to be the trend." (P39L)

\section{Concierge Practice}

Participants also discussed the concierge practice as an alternative to the traditional independent business model. Unfortunately, we could not locate peer reviewed studies regarding the feasibility of concierge practices. However, in documentation from the literature review (French et al., 2010; Jones \& Treiber, 2010; Lucier et al., 2010), researchers cited physician frustration with heavy workloads, increasing demands on time, low reimbursement, loss of autonomy, and increasing bureaucratic regulations as reasons for considering a concierge practice. Additionally, French et al. (2010) noted critics of concierge medicine argue that the model creates a two-tiered health system where the wealthy have better access to superior care and services, while Jones and Treiber (2010) suggested concierge medicine creates issues with social class disparity and access to care. Participants considered concierge medicine as an alternative business model. However, there were concerns about the viability of a concierge model in rural areas. Participant responses included the following:

- "The concierge practice model I doubt would be practical in this rural environment of East Texas—not a large enough, financially independent patient base to provide a willing group of subscribers for the patients that we would service." (P1T)

- "I know a couple of people who have concierge practices, it works great if you are in a community of people who have that kind of money to pay for that type of individualized care." (P12T)

- "It's a brave step right now, and it will only work in a specific kind of environment. I don't think people in a rural setting, like out here, can afford that type of practice." (P15T)

- "I transitioned to a concierge practice two years ago. Now I am home for dinner most nights and have more family time and less paperwork time making the same amount of money." (P12L)

- "A concierge practice is not as easy as folks like to think. These are demanding clients who don't necessarily follow medical advice." (P22L)

- "Concierge medicine negates care to the masses." (P25L)

- "Concierge medicine is great and is something I am transitioning to as a practice. I need fewer staff, save office cost, and generate a guaranteed income." (P33L)

Of the participant responses regarding the viability of business models under PPACA legislation, common statements included concerns regarding the feasibility of the ACO, PCMH, and concierge models in a rural environment because of limitations in population, infrastructure, and economics. While it was too early in the PPACA implementation process to determine the feasibility of these business models in a rural or urban environment, researchers (Shields et al., 2011; Zickafoose, Clark, Sakshaug, Chen, \& Hollingsworth, 2013) discussed the lack of integrated systems in rural areas as reasons for difficulty with ACO and PCMH implementation. Furthermore, Charles et al. (2013) and 
Okie (2012) noted an increasing number of rural surgeons entering into employment contracts with hospitals suggesting that the economics of reimbursement and the shortage of medical specialties in rural areas creates challenges for independent physicians in the development of team-based methodologies as part of the organizational structure of ACOs and PCMHs. With the diversity of patient populations and limitations in medical specialities, funding, and infrastructure, Zickafoose et al. (2013) suggested the development of team-based organizational processes should reflect the needs of individual populations.

\section{Reimbursement Models}

When exploring physician-centric business models, reimbursement processes were an integral part of the viability of the organizational model for healthcare practices. Participants discussed their concerns with possible changes to the current fee-for-service reimbursement model that included a component for value known as the value-based modifier. However, a few of the participants also noted that healthcare cannot be sustained if the payment is less than the actual cost of providing medical care. In documentation from the literature review (Berenson \& Rich, 2010; Evans, Kim, Nagarajan, \& Patro, 2010; Frakt \& Mayes, 2012; Ginsburg, 2011; Tucker, 2013), researchers have cited advantages and disadvantages of the current fee-for-service reimbursement system. Landon, Reschovsky, O'Malley, Pham, and Hadley (2011) surmised that reimbursement for physician services in the United States accounts for approximately $21.2 \%$ of total healthcare spending, while Tucker (2013) noted that the current fee-for-service model encourage physicians to increase the quantity of care, thus rewarding volume rather than outcomes. Ginsburg (2011) suggested the move toward a value-based model as a prospective payment methodology would focus upon reimbursement for broader units of service, such as episodes of care over time that incorporate quality and value into provider payments. However, opponents of reimbursement reform noted that adding a quality component resembles the capitation system under the HMO model, which failed to control healthcare costs and proffered concerns regarding the quality of patient care (Zuvekas \& Cohen, 2010). A few of the participants in this study noted concerns with reinstating an HMO-like model and felt the quality component was a way to reduce physician reimbursement. Rather than adopting previous capitation systems, Frakt and Mayes (2012) noted that the introduction of new reimbursement models in the coming years will provide quality incentives for the delivery of care. The majority of participants were in favor of a combination fee-for-service and value-based model but also voiced concerns regarding the ambiguity in defining quality. Participant responses included the following:

- "I think some aspects of a fee-for-service system work because you feel like you are getting paid for the work you are doing." (P10T)

- "Fee-for-service is not the best but there should be some quality driven compensation." $(\mathrm{P} 14 \mathrm{~T})$

- "I am concerned with how value-based care will be defined." (P16T)

- "I would welcome the reimbursement based on quality. But, I shouldn't just be penalized for bad outcomes, but recognize good outcomes and good trends as well." (P8T)

- "When you track quality you have to ask if it is skewed and if it is actual, and that could lead to some misrepresentation. Whose definition of quality? A lot of the time, what they are asking is who the low cost provider is and who can take care of patients for less money so they incentivize that." (P7T)

- "Fee for service and quality care are not mutually exclusive. They can even be a cost effective model." (P16L)

- "I am in favor of a combination fee-for-service and value-based model. But what criterion will be used to define quality care. Will it be financial?" (P18L) 
- "Defining the quality will be key as today's outcome measures seem more financially motivated in favor of the insurance companies and not patients." (P36L)

Additional participant comments regarding reimbursement models indicated there was a lack of information from the government or insurance companies regarding how PPACA reimbursement might affect their business practices. The majority of participants expressed uncertainty with regard to billing and reimbursement noting that they were not aware of (a) billing policies, (b) reimbursement pricing, (c) in-network provider status with the PPACA plans, (d) claim form submission, nor (e) the financial feasibility of accepting PPACA insurance.

\section{Principal Findings and Themes}

While implementation of many of the components of PPACA legislation were continuing through 2019, physicians were voicing concerns regarding the ability to sustain their business practices in the future. After analyzing participant perceptions and experiences of the effects of PPACA legislation related to physician-centric business models in the future, three themes emereged from participants' responses. These themes included (a) use of midlevel practitioners, (b) changes to provider practices, and (c) need for business education.

\section{Theme 1: The Use of Midlevel Practitioners}

Employing midlevel practitioners was an emergent theme from participant interviews and questionnaires regarding potential future business models under PPACA legislation. Donelan, DesRoches, Dittus, and Buerhaus (2013); French et al. (2010); and Iglehart (2013) noted the increasing use of independent midlevel practitioners as a solution to shortages in primary care physicians and to decrease healthcare costs. In a 2009 study for the National Center for Health Statistics, Park, Cherry, and Decker (2011) noted 49\% of physician practices employed a midlevel practitioner and $68.3 \%$ of physicians in large groups were more likely to use midlevel practitioners compared to physicians in solo practices. In a similar study in 2012 for the National Center for Health Statistics, Hing and Hsiao (2014) noted 77.5\% of physicians in group practices employed midlevel practitioners, an increase of $9.2 \%$ from 2009 over 2012 . While the majority of participants in this study noted the benefit of using midlevel practitioners, they opposed the use of independent midlevel practitioners without oversight by physicians. This finding aligned with information from industry articles (Donelan et al., 2013; Iglehart, 2013). Participant responses included the following:

- "My concern is that we are going to end up with a giant VA system where everyone is screened by a PA or NP and then doctors get the tougher cases, but they will be on a time clock and do only what they need to do, and when their time is up they move on. So people will get care, but not the best care." (P10T)

- "The quality of care is going to go down because a midlevel practitioner has the same level of education as a third year medical student so I don't know how many people in my waiting room want to see a third year medical student versus a physician.” (P13T)

- "The slippery slope is when these providers have to be point-of-care providers without supervision from physicians, then they should be prepared for the consequences and don't blame physicians responsible for trying to oversee multiple counties because you are trying to get by cheap." (P15T)

- "I think it will decrease the quality because you cannot compare a PA's or NP's medical knowledge with someone who goes to school and trains 3-6 years." (P8T)

- "I found that PAs and NPs have added a great deal to our practice. Our PAs and NPs offer superb care to our patients." (P14L) 
- "Some physicians don't like using PAs and NPs. I love it. They offer great care and allow me to focus on the more complex cases." (P25L)

- "PAs and NPs are offering a great alternative given the physician shortage. And with the changes in practice requirements, I am not sure how a practice can continue without them. The secret is hiring well." (P37L)

\section{Theme 2: Changes to Provider Practices}

Participant opinions regarding future business models under PPACA legislation suggested that the solo medical practice would not be a viable business model in the future. The survival of the solo medical practice may be in jeopardy because of the economic and administrative burdens of the legislation (French et al., 2010). Green, Savin, and Lu (2013) noted that the use of a traditional solo physician model was disappearing as physicians decide to join group practices or seek hospital-based employment. Satiani (2014) noted approximately $36 \%$ of physicians will own interest in their medical practice by the end of 2013 compared to $57 \%$ in 2000 . In documentation from industry articles (Kocher \& Sahni, 2010; Satiani, 2014; Shah \& Wu, 2010), researchers described increases across numerous specialties in the number of physicians joining large groups or becoming employees of hospitals because of financial security and relief from administrative and regulatory burdens. Participant responses regarding the future of the independent business model included the following:

- II predict that physicians are no longer going to be in solo or group practices, you going to be owned by a company, somehow, whether it is a hospital or part of a very large specialty practice. You will never be able to practice on your own because, the only way to provide your patient with quality care is 6 hours of sleep a day and 18 hours of work." (P16T)

- "I think the private practitioner will go away unless it is a concierge model or they will have to become employed by some type of organization because of financial issues." (P13T)

- "I think that ultimately, the healthcare laws will lead to closure of solo practices." (P16T)

- "Being employed by hospitals." (P17T; P22L)

- "Group Practice." (P2T; P9L)

- "I think solo practices are the past, except concierge practices." (P50L)

- "I guess medicine is now a business." (P52L)

\section{Theme 3: Need for Business Education}

Zonies (2009) acknowledged that physicians must possess both medical acumen and business knowledge. However, the ability to deliver medical care that is less expensive and increases quality in a highly complex industry is difficult without understanding the economics of healthcare. All participants responded that they did not receive business training in medical school and concurred with conclusions from studies by Greysen, Wassermann, Payne, and Mullan (2009). Business and health policy education were becoming essential assets because of PPACA requirements to measure the quality of healthcare in the form of economic accountability. Participants agreed that business training in medical school would be beneficial. Statements included the following:

- "No one receives business training; you just kind of learn it as you go along." (P12T)

- "OJT-there is no training in medical school with the business of medicine." (P13T)

- "The business part of conducting a medical practice was not taught in medical school or in residency. It is matter of learning it as you go along." (P2T)

- "I think it would be beneficial for medical schools to teach some sort of business training and basics in private practice." (P14T)

- "I think medical schools should include course work in practice management." (P11L)

- "I am finishing my MBA and have already been applying some of the concepts to my practice.” (P38L) 
- "We finally hired a practice administrator with an MHA, in addition to using our CPA. Now a days we have to be sure we hire business professionals in addition to our clinical staff. I guess it is a sign of the times." (P45L)

\section{Applications to Professional Practice}

The results of this study provide perspectives for developing optimal integrated delivery models that are high-value systems. Physicians do agree with the legislative intent, seeking to develop healthcare business models that are patient centered, quality focused, and cost effective.

We found that the majority of participants thought that the idea behind PPACA legislation of providing the ability for uninsured and underinsured Americans to afford health insurance was an admirable goal. Unfortunately, the design and implementation of the legislation left physicians with many unanswered questions and an unfavorable opinion of the PPACA. With an increasing emphasizes on quality outcomes and lower aggregate healthcare costs, the PPACA legislation necessitates the development of new and innovative physician practice business models. This evolution of a new, proactive, cost effective healthcare delivery paradigm suggests the use of integrated health teams consisting of diverse healthcare providers.

There were several recommendations for actions that emerged from this study including the following:

1. Further study is warranted regarding the use of midlevel practitioners as independent care providers as a solution to physician shortages. There are mixed reviews by physicians regarding this model. The concern about quality care is the central theme.

2. The PPACA supports the development of ACOs and PCMHs to decrease costs. However, these models may not be applicable because of the prior stigma of the HMO system, which left physicians wary of administrative involvement in medical decision-making and the capitation reimbursement standards. Additionally, ACOs and PCMHs may not be applicable in a rural setting because of financial constraints, patient logistics, and the lack of diversity of medical specialties.

The ACO and PCMH models are more likely to be successful through integrating physicians with hospitals in a manner that creates a sense of ownership, motivation, and certainty of governance. However, if physicians reluctantly enter into these models because they have no other option, these models are less likely to be successful. The development of delivery models should be based upon individual patient populations rather than standardization. Reimbursement reform should combine a system of fee-for-service and a quality component. However, any model should account for the myriad of issues that involve patient care, not solely based upon positive and negative outcomes.

Physicians identified the need for a business background, via training and education. They suggested the inclusion of basic business courses in medical school curriculum or for continuing education credits. This would help physicians to develop cost-effective strategies for patient care through learned business best practices. 


\section{Recommendations for Further Study}

The healthcare industry is a continually evolving system that is rapidly changing under the paradigm of the PPACA. Throughout this study, several themes emerged requiring further research. One recommendation is to perform a quantitative study on health outcomes resulting from care given by midlevel practitioners. This may offer unique perspectives on the efficacy of this practice model. Another recommendation is to conduct a qualitative analysis to determine patient perceptions of the quality of care they receive from differing physician-centric business models. Conclusions from such a study may help physicians to develop innovative models that result in high quality and cost-effective healthcare.

\section{Conclusion}

The goal of PPACA legislation is to transform the financing, organizational structure, and delivery of healthcare to slow the growth of costs and improve the quality of care for patients (Redhead, 2012). Participant perceptions included unfavorable opinions of PPACA legislation and the viability of business models under the PPACA. Additionally, three themes emerged that included (a) use of midlevel practitioners, (b) changes to provider practices, and (c) need for business education. These themes may help healthcare leaders to understand that shortfalls exist within the PPACA legislation. Physicians voiced concerns regarding the use of point-of-care, midlevel practitioners as a means to address issues with access to care. Though there are differing opinions about the quality of care given, the majority of physicians agreed that midlevel practitioners should still work under the supervision of medical doctors. This stems from the belief that these midlevel practitioners lack the level of detailed knowledge physicians acquire through medical school training. Further study is suggested here.

Physicians act in the role of a fiduciary agent with regards to the health of their patients and believe that the PPACA legislation threatens the autonomy of medical decision-making. The increase in the administrative/regulatory climate of healthcare has produced concomitant increases in physician frustration and confusion. While physicians understand that the traditional business model will need to evolve, many feel that the solo medical practice will not be a viable business model in the future because of financial constraints.

Additionally, physicians noted the need for business education in medical school to improve understanding of the economics of healthcare. Under the new paradigm of PPACA legislation, the shift in focus toward population health will require innovative models for the delivery of healthcare that are patient-centered, quality-focused, and cost-effective. 


\section{References}

Agency for Healthcare Research and Quality. (2013). Patient centered medical home resource center. Retrieved from http://www.ahrq.gov/cpi/about/otherwebsites/pcmh.ahrq.gov/index.html

Berenson, R. A., \& Rich, E. C. (2010). How to buy a medical home? Policy options and practical questions. Journal of General Internal Medicine, 25, 619-624. doi:10.1007/s11606-010-1290-4

Charles, A. G., Ortiz-Pujols, S., Ricketts, T., Fraher, E., Neuwahl, S., Cairns, B., \& Sheldon, G. F. (2013). The employed surgeon: A changing professional paradigm. JAMA Surgery, 148, 323328. doi:10.1001/jamasurg.2013.1013

Department of Health and Human Services. (2011). ACA to improve quality of care for people with Medicare. Retrieved from https://www.cms.gov/medicare/medicare-fee-for-servicepayment/sharedsavingsprogram/downloads/aco_quality_factsheet_icn907407.pdf

DiGioia III, A. M., Fann, M. M., Feng, L., \& Greenhouse, P. K. (2013). Integrating patient-and family-centered care with health policy: Four proposed policy approaches. Quality Management in Healthcare, 22, 137-145. doi:10.1097/QMH.0b013e31828bc2ee

Donelan, K., DesRoches, C., Dittus, R. S., \& Buerhaus, P. (2013). Perspectives of physicians and nurse practitioners on primary care practice. New England Journal of Medicine, 368, 18981906. doi:10.1056/NEJMsa1212938

Evans III, J. H., Kim, K., Nagarajan, N. J., \& Patro, S. (2010). Nonfinancial performance measures and physician compensation. Journal of Management Accounting Research, 22, 31-56. doi:10.2308/jmar.2010.22.1.31

Frakt, A. B., \& Mayes, R. (2012). Beyond capitation: How new payment experiments seek to find the "sweet spot" in amount of risk providers and payers bear. Health Affairs, 31, 1951-1958. doi:10.1377/hlthaff.2012.0344

French, M. T., Homer, J. F., Klevay, S., Goldman, E., Ullmann, S. G., \& Kahn, B. E. (2010). Is the United States ready to embrace concierge medicine? Population Health Management, 13, 177-182. doi:10.1089/pop.2009.0052

Ginsburg, P. B. (2011). Rapidly evolving physician-payment policy: More than the SGR. New England Journal of Medicine, 364, 172-176. doi:10.1056/NEJMhpr1004028

Ginter, E., \& Simko, V. (2010). Health differences between populations of the United States of America and the European Union. Central European Journal of Public Health, 18, 215-218. Retrieved from https://www.researchgate.net/publication/50248121_Health_differences_between_population s_of_the_United_States_of_America_and_the_European_Union

Goldsmith, J. (2011). Accountable care organizations: The case for flexible partnerships between health plans and providers. Health Affairs, 30, 32-40. doi:10.1377/hlthaff.2010.0782

Green, L. V., Savin, S., \& Lu, Y. (2013). Primary care physician shortages could be eliminated through use of teams, nonphysicians, and electronic communication. Health Affairs, 32, 1119. doi:10.1377/hlthaff.2012.1086

Greysen, S. R., Wassermann, T., Payne, P., \& Mullan, F. (2009). Teaching health policy to residents: Three-year experience with a multi-specialty curriculum. Journal of General Internal Medicine, 24, 1322-1326. doi:10.1007/s11606-009-1143-1 
Hing, E., \& Hsiao, C. (2012). State variability in supply of office-based primary care providers: United States, 2012. National Center for Health Statistics, Data Brief, 151, 1-8. Retrieved from http://www.cdc.gov/nchs/data/databriefs/db151.pdf

Houghton, C., Casey, D., Shaw, D., \& Murphy, K. (2013). Rigour in qualitative case-study research. Nurse Researcher, 20, 12-17. Retrieved from http://www.ncbi.nlm.nih.gov/pubmed/23520707

Huddle, T. S., \& Centor, R. M. (2011). Retainer medicine: An ethically legitimate form of practice that can improve primary care. Annals of Internal Medicine, 155, 633-635. doi:10.7326/00034819-155-9-201111010-00013

Hunter, C., \& Baum, N. (2012). Physician-hospital alignment: Employment lite. The Journal of Medical Practice Management, 28, 260-263. Retrieved from http://saskatoonlibrary.ca/eds/item?dbid=edo\&an=86207767

Iglehart, J. K. (2011). Doctor-workers of the world, unite! Health Affairs, 30, 556-558. doi:10.1377/hlthaff.2011.0286

Iglehart, J. K. (2013). Expanding the role of advanced nurse practitioners - Risks and rewards. New England Journal of Medicine, 368, 1935-1941. doi:10.1056/nejmhpr1301084

Jones, J. H., \& Treiber, L. (2010). Concierge medicine: The perfect storm? Implications for nurse practitioners. The Journal for Nurse Practitioners, 6, 109-114. doi:10.1016/j.nurpra.2009.11.002

Kingsdale, J. (2014). After the false start: What can we expect from the new health insurance marketplaces? New England Journal of Medicine, 370, 393-396. doi:10.1056/NEJMp1315956

Kocher, R., \& Sahni, N. R. (2010). Physicians versus hospitals as leaders of accountable care organizations. New England Journal of Medicine, 363, 2579-2582. doi:10.1056/NEJMp1011712

Landon, B. E., Reschovsky, J. D., O’Malley, A. J., Pham, H. M., \& Hadley, J. (2011). The relationship between physician compensation strategies and the intensity of care delivered to Medicare beneficiaries. Health Services Research, 46, 1863-1882. doi:10.1111/j.1475-6773.2011.01294.x

Longworth, D. L. (2013). Accountable care and patient centered medical homes: Implications for office-based practice. Cleveland Clinic Journal of Medicine, 80, eS36-eS40. doi:10.3949/ccjm.80.e-s1.08

Lucier, D. J., Frisch, N. B., Cohen, B. J., Wagner, M., Salem, D., \& Fairchild, D. G. (2010). Academic retainer medicine: An innovative business model for cross-subsidizing primary care. Academic Medicine, 85, 959-964. doi:10.1097/ACM.0b013e3181dbe19e

Malach, M., \& Baumol, W. J. (2012). Opportunities for cost reduction of medical care: Part 3. Journal of Community Health, 37, 888-896. doi:10.1007/s10900-011-9534-8

Marco, C. A., Moskop, J. C., Schears, R. M., Stankus, J. L., Bookman, K. J., Padel, A. I., ... Bryant, E. (2012). The ethics of health care reform: Impact on emergency medicine. Academic Emergency Medicine, 19, 461-468. doi:10.1111/j.1553-2712.2012.01313.x

Martin, A. B., Lassman, D., Washington, B., \& Catlin, A. (2012). Growth in U.S. health spending remained slow in 2010: Health share of gross domestic product was unchanged from 2009. Health Affairs, 31, 208-219. doi:10.1377/hlthaff.2011.1135

Mazurenko, O., \& O'Connor, S. J. (2012). The impact of physician job satisfaction on the sustained competitive advantage of health care organizations. Journal of Management Policy and Practice, 13, 21-34. Retrieved from 
http://digitalscholarship.unlv.edu/cgi/viewcontent.cgi?article=1181\&context=community_heal th_sciences_fac_articles

McClellan, M. (2011). Reforming payments to healthcare providers: The key to slowing healthcare cost growth while improving quality? The Journal of Economic Perspectives, 25, 69-92. doi:10.1257/jep.25.2.69

McClellan, M., McKethan, A. N., Lewis, J. L., Roski, J., \& Fisher, E. S. (2010). A national strategy to put accountable care into practice. Health Affairs, 29, 982-990. doi:10.1377/hlthaff.2010.0194

Moore, L. G., \& Wasson, J. H. (2007). The ideal medical practice model: Improving efficiency, quality, and the doctor-patient relationship. Family Practice Management, 14, 20-24. Retrieved from http://www.aafp.org/fpm/2007/0900/p20.pdf

Murray, C. J. L., \& Frenk, J. (2010). Ranking 37th:Mmeasuring the performance of the U.S. health care system. New England Journal of Medicine, 362, 98-99. doi:10.1056/NEJMp0910064

Nutting, P. A., Crabtree, B. F., Miller, W. L., Stange, K. C., Stewart, E., \& Jaén, C. (2011). Transforming physician practices to patient-centered medical homes: Lessons from the national demonstration project. Health Affairs, 30, 439-445. doi:10.1377/hlthaff.2010.0159

Okie, S. (2012). The evolving primary care physician. New England Journal of Medicine, 366, 18491853. doi:10.1056/nejmp1201526

Park, M., Cherry, D., \& Decker, S. L. (2011). Nurse practitioners, certified nurse midwives, and physician assistants in physician offices. National Center for Health Statistics, Data Brief, 69, 1-8. Retrieved from http://www.cdc.gov/nchs/data/databriefs/db69.htm

Payton, B. (2012). Physician-hospital relationships: From historical failures to successful new kids on the block. The Journal of Medical Practice Management, 27, 359-364. Retrieved from http://www.corazoninc.com/downloads/articles/2012/ppa/Physician-HospitalRelationships.pdf

Proctor, D. B., \& Young-Adams, A. P. (2011). Kinn's the medical assistant: An applied learning approach (11th ed.). St. Louis, MO: Elsevier Saunders.

Quaye, R. Q. (2014). The Patient Protection and Affordable Care Act (ACA) of 2010 and Ohio physicians. Leadership in Health Services, 27, 116-125. doi:10.1108/LHS-10-2012-0037

Redhead, C. S. (2012). Budget control act: Potential impact of sequestration on health reform spending (Report No. 7-5700/R42051). Retrieved from https://www.fas.org/sgp/crs/misc/R42051.pdf

Satiani, B. (2014). Health care update: Hospital employment or private practice. Perspectives in Vascular Surgery and Endovascular Therapy, 25, 46-52. doi:10.1177/1531003513510952

Shah, P. B., \& Wu, S. H. (2010). Health care reform's impact on physician practices. Physical Medicine and Rehabilitation, 2, 767-770. doi:10.1016/j.pmrj.2010.07.005

Shortell, S. M., Casalino, L. P., \& Fisher, E. S. (2010). How the center for Medicare and Medicaid innovation should test accountable care organizations. Health Affairs, 29, 1293-1298. doi:10.1377/hlthaff.2010.0453

Sommers, B. D., \& Bindman, A. B. (2012). New physicians, the Affordable Care Act, and the changing practice of medicine. Journal of the American Medical Association, 307, 1697-1698. doi:10.1001/jama.2012.523

Tracy, S. J. (2010). Qualitative quality: Eight big-tent criteria for excellent qualitative research. Qualitative Inquiry, 16, 837-851. doi:10.1177/1077800410383121 
Tucker, M. E. (2013). Physician pay is changing. British Medical Journal, 346, 1540-1541. doi:10.1136/bmj.f1540

VanVactor, J. D. (2013). Leveraging the patient-centered medical home (PCMH) model as a health care logistics support strategy. Leadership in Health Services, 26, 96-106. doi:10.1108/17511871311319696

Wise, C. G., Alexander, J. A., Green, L. A., \& Cohen, G. R. (2012). Physician organization-practice team integration for the advancement of patient-centered care. Journal of Ambulatory Care Management, 35, 311-322. doi:10.1097/JAC.0b013e3182606e7c

Wolinsky, F. D. (1982). Why physicians choose different types of practice settings. Health Services Research, 17, 399-419. Retrieved from http://www.ncbi.nlm.nih.gov/pmc/articles/PMC1068700/

Yin, R. K. (2014). Case study research: Design and methods (5th ed.). Thousand Oaks, CA: Sage Publications.

Zickafoose, J. S., Clark, S. J., Sakshaug, J. W., Chen, L. M., \& Hollingsworth, J. M. (2013). Readiness of primary care practices for medical home certification. Pediatrics, 131, 473-482. doi:10.1542/peds.2012-2029

Zismer, D. K. (2011). The psychology of organizational structure in integrated health systems. Physician Executive Journal, 37, 36-43. Retrieved from http://nneahe.ache.org/Documents/The\%20Psychology\%20of\%20Organizational\%20Structure \%20in\%20Integrated\%20Health\%20Systems_DZ\%20Article.pdf

Zonies, K. (2009, January/February). Why primary care physicians should be self-employed. Physician Executive Journal, 35, 16-19. Retrieved from http://www.freepatentsonline.com/article/Physician-Executive/192693959.html

Zuvekas, S. H., \& Cohen, J. W. (2010). Paying physicians by capitation: Is the past now prologue? Health Affairs, 29, 1661-1666. doi:10.1377/hlthaff.2009.0361

The International Journal of Applied Management and Technology (IJAMT), sponsored by Walden University's School of Management, is a peer-reviewed, online journal that addresses contemporary national and international issues related to management and technology. The objectives of the IJAMT are to: (a) encourage collaborative and multi-disciplinary examinations of important issues in business and technology management, and (b) engage scholars and scholar-practitioners in a dynamic and important dialogue.

Walden University Publishing: http://www.publishing.waldenu.edu 